\title{
Memória e justiça: a psicologia no atendimento às vítimas de violência
}

\author{
Bruno Cervilieri Fedri*
}

\begin{abstract}
Resumo
$\mathrm{O}$ artigo tem como objetivo apresentar a atuação do(a) psicólogo(a) no atendimento à vítima de violência realizado de forma interdisciplinar junto às políticas públicas e o acolhimento de seus testemunhos, tendo como foco principal o oferecimento do acesso à justiça para além do atendimento clínico. Este trabalho foi desenvolvido para analisar alguns desafios cotidianos enfrentados por psicólogos e psicólogas, como: as formações dissonantes com relação às demandas da realidade social, a desarticulação entre ética profissional e os direitos humanos e o favorecimento das intervenções clínicas em detrimento de ações interdisciplinares. Observou-se que estes desafios colaboram para que o atendimento psicológico das vítimas de violência seja caracterizado como um trabalho a ser realizado em âmbito privado, que favorece a criação e o fortalecimento das políticas públicas. Desta forma, este artigo procura reafirmar o compromisso da Psicologia com os Direitos Humanos e a memória das vítimas, privilegiando metodologias interdisciplinares e a participação destas para o exercício da cidadania.

Palavras chave: vítima, violência, justiça
\end{abstract}

\section{Memory and Justice: psychology in caring for victims of violence}

\begin{abstract}
The article aims to present the psychologist's role in dealing with victims of violence carried out in an interdisciplinary way with public policies and the reception of their testimonies, with the focus being on access to justice beyond clinical care. This work was developed to analyze some daily challenges faced by psychologists and psychologists, such as dissonant formations regarding the demands of social reality, the disarticulation between professional ethics and human rights, and the favoring of clinical interventions to the detriment of interdisciplinary actions. It was observed that these challenges collaborate so that the psychological care of the victims of violence is characterized as a work to be carried out in private, that favors the creation and the strengthening of public policies. In this way, this article seeks to reaffirm the commitment of Psychology to Human Rights and the memory of victims, favoring interdisciplinary methodologies and their participation in the exercise of citizenship and access to rights.
\end{abstract}

Key words: victim, violence, justice

* Mestre em Psicologia Clínica (PUCSP). Coordenador Técnico do Centro de Referência e Apoio à Vítimas de Violência - CRAVI da Secretaria da Justiça e da Defesa da Cidadania do Estado de São Paulo. 


\section{Introdução}

As estatísticas de violência no Brasil são alarmantes e já conhecidas, dada sua gravidade e presença desde as grandes cidades até os municípios com menor número de habitantes. O Atlas da Violência, publicação mais recente até o momento, aponta que no Brasil foram assassinadas mais de 59.000 pessoas no ano de 2015. As regiões norte e nordeste apresentaram aumento no número de homicídios de mais de 100\% em comparação com os estudos anteriores, tendo como principais expoentes os estados do Rio Grande do Norte, Sergipe e Maranhão (Cerqueira, Lima, Bueno, Valencia, Hanashio, Machado \& Lima, 2017).

Segundo o Anuário Brasileiro de Segurança Pública (2017) do Fórum Brasileiro de Segurança Pública, a cada nove minutos uma pessoa é assassinada no Brasil, índice de violência que supera os de países em guerra declarada, como a Síria.

Mais precisamente no Estado de São Paulo observou-se, no entanto, o recrudescimento no número de homicídios, de 21 por cem mil habitantes para 12 homicídios por cem mil, uma diminuição de $44 \%$ de acordo com o Atlas da Violência de 2017. Na região do Grande $\mathrm{ABC}$ observa-se uma expressiva variação dos números de homicídio, sendo São Caetano do Sul apresentando 7 homicídios por cem mil enquanto Diadema apresenta mais que o dobro, 17 homicídios por cem mil habitantes (Cerqueira, et al., 2017).

São números alarmantes que servem para reflexão, especialmente para futuros e futuras profissionais da Psicologia que todos os anos iniciam seus estudos comprometidos com a singularidade dos indivíduos e confiantes na potencialidade transformadora do diálogo. A violência, vale ressaltar, é um dos fenômenos mais desafiadores para o trabalho dos profissionais da Psicologia justamente porque atenta contra aquilo que este profissional tem como principal instrumento: sua subjetividade. A violência emudece, hierarquiza, submete e objetaliza. Pode ser ruidosa, mas também silenciosa e imperceptível e para que ela seja objeto de atenção e transformação é necessária a conscientização de sua dimensão. (Souza, 2006)

Não raro, diversos estudantes de Psicologia desconhecem a realidade social violenta que os permeia e tal desconhecimento desfavorece a criação e manutenção de práticas coletivas e que favoreçam a cidadania e o acesso à justiça por parte da população - e estes temas são de especial importância para o psicólogo. Além disso, é comum observar a ausência dos princípios e valores relacionados aos direitos humanos no trabalho realizado por alguns profissionais, especialmente inseridos nas grandes especialidades da Psicologia, como a Psicologia Jurídica. A dignidade da pessoa humana e seu direito para com o acesso à justiça são pressupostos para se trabalhar com vítimas de violência, especialmente vítimas de crimes contra a vida. (Schilling \& Kamimura, 2009).

Observa-se também considerável preocupação com as intervenções clínicas e com o desenvolvimento emocional da vítima em detrimento ao oferecimento de um suporte que também conte com o seu acesso à justiça e o exercício da sua cidadania, reforçando assim o lugar da Psicologia na área da Justiça.

O código de ética profissional do psicólogo (2005), por meio de seus princípios fundamentais, aponta para a importância de se basear o trabalho profissional na promoção da liberdade, da igualdade e na integralidade do ser humano e sua atuação será realizada com responsabilidade social, analisando crítica e historicamente a realidade política, econômica, social e cultural. (Código de ética profissional do psicólogo, 2005)

O Conselho Regional de Psicologia de São Paulo, por meio de seu editorial "Entremeio: Psicologia e Política" (2017), justifica o não envolvimento da Psicologia nas questões sociais por meio de uma análise histórica, na qual a ditadura brasileira predominou, entre os anos de 1964 e 1985, sendo a Psicologia fundada no Brasil em 1971. Além disso, a dicotomia entre ciências humanas e ciências sociais fez valer a Psicologia como uma profissão na qual o social não poderia ser abarcado, limitando a mesma nos estudos relacionados ao indivíduo e suas transformações.

$\mathrm{Na}$ atualidade, os conselhos regionais bem como o Conselho Federal de Psicologia se unem no sentido de reforçar a importância da Psicologia nos contextos sociais e políticos, por meio do posicionamento crítico com relação às políticas públicas e as violações de direitos, especialmente das populações vulneráveis, como LGBTs, populações negra e indígena, migrantes, pessoas com deficiência, população em situação de rua, mulheres, crianças, adolescentes, idosos, soropositivos entre muitos outros. (Conselho Regional de Psicologia de São Paulo. Políticas públicas, reforma e desmonte dos direitos sociais, 2017).

As universidades, por sua vez, demonstram interesse cada vez maior nas aplicações institucionais e comunitárias da Psicologia. Os estatutos e leis específicas para a regulamentação de direitos, como o Estatuto da Criança e do Adolescente bem como a Lei Maria da Penha, hoje são transmitidos às alunas(os) como um importante instrumento de intervenção a ser realizado 
juntamente com os demais profissionais que fazem parte da rede de serviços.

O presente artigo, portanto, tem como objetivo apresentar algumas particularidades da atuação do(a) psicólogo(a) no atendimento à vítima de violência urbana, como a atuação interdisciplinar e o acolhimento do testemunho das vítimas de violência, tendo como foco principal o oferecimento do acesso à justiça para além do atendimento clínico, reafirmando o compromisso da Psicologia com os direitos humanos e a memória das vítimas, privilegiando metodologias interdisciplinares e a participação desta para o exercício pleno de sua cidadania e acesso à direitos.

\section{Do privado ao público - Um desafio para a Psicologia}

Conforme afirmado anteriormente, é comum observar o comprometimento do psicólogo e da psicóloga nas intervenções clínicas a serem realizadas junto à vítima de violência em detrimento às intervenções relacionadas aos aspectos sociais que a temática comporta. A violência por vezes é ainda tratada pelo profissional da Psicologia como algo da ordem do privado, a ser elaborada nos consultórios e desconectada da rede de instituições de assistência, saúde e justiça.

A violência contra crianças e adolescentes é um exemplo. Mesmo que suspeita, esta deve obrigatoriamente ser comunicada ao Conselho Tutelar, conforme o art. 13 do Estatuto da Criança e do Adolescente (Brasil, 2002). Uma ameaça de morte realizada contra uma mulher vítima de violência, especialmente após a realização da medida protetiva, deve ser objeto de queixa criminal, segundo parágrafo $2^{\circ}$ da lei Maria Penha (Brasil, 2006). Um ato de discriminação racial deve ser encaminhado para a coordenação de políticas para a população negra e indígena, segundo decreto estadual 54.529/2009. (Brasil, 2009).

Existem ainda outros exemplos: pessoas com deficiência e idosos, quando vítimas de violência, podem ser encaminhadas para delegacias especializadas, algumas delas contando com funcionários habilitados para se comunicarem por meio de Libras. Homossexuais, lésbicas, bissexuais e transexuais, graças ao decreto 54.032/2009, podem procurar a coordenação de políticas para a diversidade sexual em caso de discriminação.

Todas estas possibilidades de encaminhamentos, além de complementarem o trabalho clínico realizado com a vítima de violência, reforçam o compromisso do profissional da Psicologia com o ambiente, com a realidade social que o permeia.
É importante ressaltar, porém, que alguns desafios ainda não foram superados. No Brasil, não existem políticas regulamentadas para a assistência e a proteção das vítimas de violência urbana. $\mathrm{O}$ artigo 245 da constituição federal afirma que:

A lei disporá sobre as hipóteses e condições em que o Poder Público dará assistência aos herdeiros e dependentes carentes de pessoas vitimadas por crime doloso, sem prejuízo da responsabilidade civil do autor do ilícito. (Brasil, 1988)

Apesar de importante para a efetiva responsabilização do Estado para com a assistência às vítimas de violência, não especifica de que maneira tal assistência será oferecida nem por qual profissional será realizado o apoio.

$\mathrm{O}$ art. 278 da Constituição do Estado de São Paulo afirma que o poder público promoverá programas especiais, admitindo a participação de entidades não governamentais em diversas ações, entre elas na criança e manutenção de serviços de prevenção, orientação, recebimento e encaminhamento de denúncias de violência. Com base neste artigo o Governo do Estado de São Paulo mantém um programa público de atendimento a vítima que ainda busca sua municipalização para as demais regiões do Estado (Constituição do Estado de São Paulo, 1989)

O próprio Estatuto da Criança e do Adolescente, mais especificamente em seu artigo 150, descreve que "cabe ao poder judiciário, na elaboração de sua proposta orçamentária, prever recursos para a manutenção de equipe interprofissional, destinada a assessorar a Justiça da infância e da juventude". Este artigo legitimou o lugar e a função dos psicólogos e psicólogas na justiça, antes ocupando funções escusas e não certificadas (Brito, 2012). Entretanto, ainda são parcas as oportunidades oferecidas para o aumento do contingente destes profissionais neste importante âmbito.

Observa-se, portanto que, apesar de alguns avanços, os psicólogos e psicólogas ainda encontram diversos obstáculos para sua atuação junto à justiça, sendo este ambiente potencial para o favorecimento da elaboração da violência sofrida pela vítima e para a legitimação de seu sofrimento como algo a ser concebido e transformado no âmbito público.

$\mathrm{O}$ atendimento às vítimas de violência, para que seja realizado com o devido cuidado e efetividade, depende do apoio de diversas instituições, que além de garantirem o acesso à justiça e aos direitos das vítimas, legitimam o lugar desta ao passo que colaboram para a 
elaboração e manutenção de políticas públicas voltadas ao tema da violência.

Neste campo, a Psicologia tem muito a oferecer, especialmente quando trabalhada de forma interdisciplinar.

\section{Interdisciplinaridade: Psicologia, Serviço Social e Direito}

Uma vez apresentadas algumas das particularidades e dos desafios relacionados ao atendimento às vítimas de violência, bem como apresentados os índices expressivos da violência urbana no Brasil, cabe-nos refletir a respeito das metodologias e dos procedimentos necessários para que seja possível compreender este fenômeno em sua dimensão ético-política.

Com o fim da ditadura e o estabelecimento da democracia no Brasil, impulsionada também pelos diversos tratados internacionais de direitos humanos sob os quais o país é signatário, observou-se, por meio da organização dos movimentos sociais, a criação de diversas instituições não-governamentais com o objetivo de enfrentar as violações de direitos humanos, especialmente aquelas cometidas pelo regime militar.

Entre elas estavam o Centro de Direitos Humanos e Educação Popular do Campo Limpo (CDHEP), fundado em 1981 e oriundo da Comissão Pastoral de Direitos Humanos - uma das organizações mais antigas da cidade de São Paulo - e a Sociedade Santos Mártires, fundada em 1987.

Um ano depois, em 1988, ocorreu a inauguração do CRAMI - Centro Regional de Atenção aos Maus-tratos na Infância, na cidade de Santo André, estabelecendo-se como uma das mais referenciais instituições de apoio às vítimas de violência na região.

Estas três instituições, por meio de seus diversos projetos interventivos, têm em comum a manutenção de uma equipe formada por psicólogos, assistentes sociais e advogados, que carregam, nos princípios fundamentais de seus respectivos códigos de ética profissional, o compromisso com a cidadania, os direitos humanos e a justiça.

Afirma o código de ética profissional dos assistentes sociais, como um de seus princípios fundamentais:

II. Defesa intransigente dos direitos humanos e recusa do arbítrio e do autoritarismo; III. Ampliação e consolidação da cidadania, considerada tarefa primordial de toda sociedade, com vistas à garantia dos direitos civis sociais e políticos das classes trabalhadoras; IV. Defesa do aprofundamento da democracia, enquanto socialização da participação política e da riqueza socialmente produzida (Conselho Federal de Serviço Social, 1993).
O código de ética do advogado, por sua vez, no seu art. $2^{\circ}$, afirma que o advogado, indispensável à administração da Justiça, é defensor do Estado democrático de direito, da cidadania, da moralidade pública, da Justiça e da paz social, subordinando a atividade do seu Ministério Privado à elevada função pública que exerce.

O código de ética do Psicólogo, dentre seus princípios fundamentais, orienta que: I. O psicólogo baseará o seu trabalho no respeito e na promoção da liberdade, da dignidade, da igualdade e da integridade do ser humano, apoiado nos valores que embasam a Declaração Universal dos Direitos Humanos.

Juntas, estas disciplinas favorecem a interdisciplinaridade, modelo de trabalho fundamental para o atendimento efetivo às populações vulneráveis, especialmente às vítimas de violência. A interdisciplinaridade difere da multidisciplinaridade, tendo em vista que a primeira busca compartilhar com as mais diversas áreas do saber o mesmo objeto de estudo, enquanto a multidisciplinaridade possui diferentes objetos.

Além disso, é importante ressaltar que a interdisciplinaridade não se caracteriza unicamente pela união de diferentes profissionais. Para Rodrigues On (1995) a interdisciplinaridade é uma postura profissional, cuja potencialidade é reconhecida justamente na sustentação do recorte das disciplinas.

Para Souza (2009) o conceito de interdisciplinaridade é inacabado, por ser dinâmico e processual. Ela nos convida a um olhar múltiplo sobre as diversas manifestações e determinações da realidade humana e social, permitindo-nos superar o modelo tradicional de ciência, que tende pela fragmentação dos vários aspectos da vida.

O profissional da Psicologia, considerando a interdisciplinaridade, tem a possibilidade de realizar o seu trabalho com maior compromisso ético e político, pois sabe que suas intervenções poderão ser complementadas por outros profissionais e instituições, realocando suas intervenções para o campo social. Isto significa dizer que o psicólogo, uma vez consciente dos limites e possibilidades de suas intervenções, poderá acolher um paciente para atendimento clínico enquanto encaminha suas demandas jurídicas e sociais para os profissionais pertinentes, estabelecendo uma rede interdisciplinar de intervenções.

É, portanto, na interdisciplinaridade, que uma demanda como a de Justiça, a principal das vítimas de violência, poder ser acolhida. Enquanto o psicólogo realiza as entrevistas e atendimento com o objetivo de dimensionar os efeitos e sintomas da violência sofrida, o assistente social realiza o levantamento da situação 
socioeconômica da vítima e a auxilia a refletir sobre seu lugar social. (Conselho Federal de Ética do Assistente Social,1993). O profissional da área do Direito, por fim, realiza o levantamento dos fatos relacionados ao crime. (Secretaria da Justiça e da Defesa da Cidadania, 2012).

Estes profissionais ainda realizarão encaminhamentos para a rede de recursos assistencial, de saúde e de justiça, contando com as diversas instituições que atravessam este atendimento, para que elas possam realizar as orientações jurídicas e sociais necessárias, encaminhando às vítimas para a Defensoria Pública do Estado com o objetivo de dirimirem dúvidas cíveis e para o Ministério Público, para a realização dos esclarecimentos acerca do processo criminal. Os Centros de Referência de Assistência Social (CRAS), bem como os Centros de Referência Especializados de Assistência Social (CREAS) também podem realizar importantes intervenções, avaliando junto às vítimas a eventual necessidade de inserção em projetos socioassistenciais, tendo como produto final e fundamental destas intervenções a viabilização das vozes das vítimas e a garantia de seus direitos.

\section{Memória e Testemunho - Formas de Romper a Repetição e o Silenciamento}

Em 6 de Setembro de 2017 foi inaugurado, em Berlim, o Munich 1972 Massacre Memorial, o memorial das vítimas do atentado terrorista das olimpíadas de Munique, que deixou dezessete mortos, sendo onze deles atletas israelenses.

Sua arquitetura chama a atenção: um espaço cinzento, talhado em uma encosta de um parque, como que demonstrando uma ferida aberta, onde uma tela exibe notícias do atentado e apresenta os perfis bibliográficos das vítimas, repetidamente (como algo próprio do traumático).

Dez anos antes, em 2007, foi inaugurado em São Paulo o Parque da Juventude, mesmo local onde, em 1992, foram mortos 111 presos no crime conhecido nacional e internacionalmente como o massacre do Carandiru. Sua estrutura, no entanto, em nada relembra a violência cometida contra aquela população carcerária. Os três prédios mantidos foram transformados em escolas técnicas enquanto o muro que abrigava os guardas e algumas celas, tiveram seus significados esvaziados.

Estes dois exemplos citados apontam formas antagônicas no trato com a violência ocorrida. Enquanto na Alemanha os crimes contra a vida encontram no espaço público um lugar para o registro do trauma com objetivos de rompimento da repetição da violência, no Brasil a tentativa de apagar o ocorrido favorece sua reincidência.
Para Ocariz (2015) o não reconhecimento da violência não apenas impossibilita sua memória, mas também deslegitima a dor e o sofrimento das vítimas, seus familiares e testemunhos. A autora descreve as caracterizações e a importância do testemunho:

\begin{abstract}
"Aquilo que é narrado de forma testemunhal volta a adquirir a temporalidade do presente - mesmo que tenha acontecido há muito tempo - já que a emoção manifestada por aquele que viveu e relembra a experiência, tem um poder que poucas histórias possuem (p. 33)"
\end{abstract}

As vítimas de violência sofrem diversos tipos de revitimizações durante o percurso que realizam junto às instituições de justiça, são estigmatizadas e por vezes indiferenciadas diante de seus próprios algozes. São responsabilizadas pelo ocorrido e orientadas a deixar o sofrimento de lado, como se este fosse algo a ser escolhido. Sua fala, portadora de uma história de dor e sofrimento se apresenta como algo contagioso e insuportável de se ouvir. (Secretaria da Justiça e da Defesa da Cidadania, 2012).

Por estes motivos, seu testemunho, imprescindível para a elaboração da violência, tende a ser silenciado e sua busca por justiça descontinuada. Ocorre que o silêncio trabalha contra a transformação.

Assim, o psicólogo deve, diante de uma vítima de violência, manter seu compromisso ético e político de, por meio do testemunho desta, auxiliar na transformação de sua realidade, apostando na construção e reconstrução de sua memória, favorecendo a criação e manutenção de espaços coletivos que potencializem o caráter público de seu sofrimento e uma possível ação de cidadania sobre o ocorrido. Para tanto, o psicólogo deve atuar em duas perspectivas, trabalhando junto a criação e manutenção de políticas públicas de direitos humanos, bem como fomentando a realização de grupos, que segundo Zimermann (1997) podem ser tanto operativos quanto psicoterápicos.

Nos grupos operativos, onde a finalidade é trabalhar com uma tarefa comum, podem ser discutidos temas que remetem à cidadania e aos direitos humanos das vítimas com o objetivo de oferecer maior empoderamento e autonomia às mesmas e assim colaborar para a participação das vítimas na construção das políticas públicas. Ao final dos encontros os membros do grupo podem organizar um material informativo de orientação para as vítimas, constituindo-se assim em uma segunda tarefa.

Nos grupos psicoterápicos, por sua vez, podem ser trabalhadas as significações relativas à violência sofrida bem como a construção de significados cuja violência não 
permitiu elaborar. Trata-se assim de um dispositivo que teria como objetivo a melhoria da situação de patologia dos indivíduos (Zimmerman, 1997) considerando a memória das vítimas como um importante instrumento para tanto.

Memória neste contexto, é importante ressaltar, não deve ser entendida como mera recordação do ocorrido. A memória da vítima de violência a reconduz ao lugar singular de sua experiência, lugar no qual ninguém pode assumir e por isso, ninguém pode transformar senão por meio de seu desejo. Os grupos psicoterápicos podem se apresentar como importantes dispositivos para favorecer a evidenciação destas memórias fundadas na dinâmica inconsciente grupal.

Contando e recontando sua experiência junto ao outro, a vítima de violência pode deixar o isolamento e constatar o caráter coletivo de seu sofrimento, podendo se aproximar de outras vítimas, propor a criação de políticas públicas mais eficazes para sua assistência e acessar a justiça, empoderada de seus direitos.

\section{Considerações finais}

A Psicologia pode fazer ainda mais do que auxiliar a vítima a atravessar o lugar de objeto da violência para o lugar de sujeito de suas escolhas. Pode, junto com a vítima, auxiliar na transformação do sujeito em cidadão de direitos, acolhendo a vítima de forma a garantir a singularidade de sua demanda, colaborando para a legitimação de seu sofrimento e convidando-a a se apropriar dos espaços públicos, favorecendo sua autonomia.

Desta forma, o psicólogo poderá reafirmar o compromisso da Psicologia com os Direitos Humanos e a memória das vítimas, privilegiando metodologias interdisciplinares e a participação destas para o exercício de sua cidadania e acesso à direitos.

\section{Referências}

Anuário Brasileiro de Segurança Pública (2017). Fórum Brasileiro de Segurança Pública. Disponível em: http://www.forumseguranca.org.br/wp-content/ uploads/2017/12/ANUARIO_11_2017.pdf. Acesso em: 07 nov.2017.
Brasil (2006). Casa Civil da Presidência da República. Lei $n^{0} 11.340$, de 7 de agosto de 2006. Disponível em: < http://www.planalto.gov.br/ccivil_03/_Ato20042006/2006/Lei/L11340.htm>. Acesso em: 07 nov. 2017.

Brasil (1998). Constituição da República Federativa do Brasil. Artigo 245. Brasília, DF: Senado Federal: Centro Gráfico, 1988.

Brasil (2002). Estatuto da criança e do adolescente: Lei federal no 8069, de 13 de julho de 1990. Rio de Janeiro: Imprensa Oficial, 2002.

Brasil (2009). Decreto n. 54.429 de 9 de junho de 2009. Cria e Organiza, na Secretaria da Justiça e da Defesa da Cidadania, a Coordenação de Políticas para a População Negra e Indígena. São Paulo. Assembleia Legislativa. 2009.

Brito, L. M. T. (2012) Anotações Sobre Psicologia Jurídica. Revista Psicologia Ciência e Profissão. 32, 194,205.

Código de Ética e Disciplina da OAB (1995). Disponível em < http://www. oab.org.br/content/pdf/legislacaooab/codigodeetica.pdf $>$ Acesso em: $07 / 11 / 2017$.

Conselho Federal de Ética do Assistente Social (1993) Brasília: CFESS, 1993.

Código de Ética Profissional do Psicólogo. Conselho Federal de Psicologia. Brasília-DF, 2005.

CONSELHO REGIONAL DE PSICOLOGIA DE SÃO PAULO (2017). Editorial: Entremeio: Psicologia e Política. Revista do Conselho Regional de Psicologia de São Paulo. Edição no 190 Julho/Agosto.

CONSELHO REGIONAL DE PSICOLOGIA DE SÃO PAULO (2017). Políticas públicas, Reforma e Desmonte dos Direitos Sociais. Revista do Conselho Regional de Psicologia de São Paulo. Edição no 190 Julho/Agosto.

Constituição do Estado de São Paulo (1989). Artigo 278. São Paulo, 1989.

SECRETARIA DA JUSTIÇA E DA DEFESA DA CIDADANIA do Estado de São Paulo. (2012) Metodologia de Atendimento do Centro de Referência e Apoio à Vítima - CRAVI.

Cerqueira, D., Lima, R.S., Bueno, S., Valencia, L.I., Hanashiro, O., Machado, R.H.G \& Lima (2017). Ipea e FBSP. Fórum Brasileiro de Segurança. Atlas da Violência 2017. Disponível em <http://www.ipea.gov.br/atlasviolencia/ download/2/2017> Acesso em 07 nov. 2017.

Ocariz, M. C. (2015) Violência de Estado na Ditadura Civil-militar Brasileira (1964-1985) - Efeitos Psíquicos e Testemunhos Clínicos. Editora Escuta, São Paulo: 2015.

Schilling, F.\& Kamimura, A. (2009) Direitos Humanos e Vítimas de Violência: Experiências e Dilemas do Atendimento. Revista Perspectivas 36. P. 41-71, jul./dez.

SECRETARIA DA JUSTIÇA E DA DEFESA DA CIDADANIA. Coordenação de Políticas para a Comunidade Negra e Indígena e Coordenação de Políticas para a Diversidade Sexual. Disponível em <www.justica.sp.gov. br> Acesso em 07 nov. 2017.

Souza, M . L. R. (2006) Violência. São Paulo: Casa do Psicólogo

Souza. M. F. (2009). Interdisciplinaridade, Serviço Social e Penas Alternativas: Entre a Tutela Institucional e a Emancipação dos Sujeitos em Conflito com a Lei. Serviço Social Revista. Londrina, V. 12, n. 1, p. 43-63, jul/dez

RODRIGUES ON. M. L. (1995) O Serviço Social e a perspectiva Interdisciplinar. In: O Uno e o Múltiplo nas relações entre as áreas do saber. (Org.) Martinelli, M.L; Rodrigues On, M.L e MUCHAIL, S. T. Ed. Cortez, São Paulo

Zimermann, D. E. (1997) Como Trabalhamos com Grupos. Porto Alegre. Artes Médicas, 1997.

Submetido em: 22-8-2018

Aceito em: 14-4-2019 